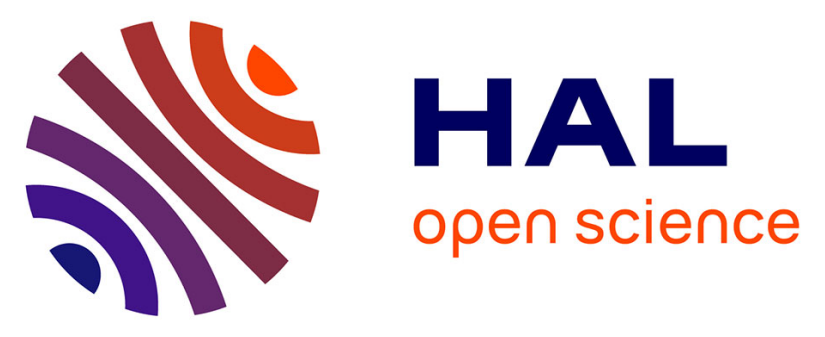

\title{
Lead and zinc concentrations in household dust and toenails of the residents (Estarreja, Portugal): a source-pathway-fate model
}

\author{
A. Paula Paula Marinho Reis, M. Cave, A. J Sousa, J. Wragg, M. Rangel, A. \\ Oliveira, C. Patinha, F. Rocha, T. Orsiere, Y. Noack
}

\section{To cite this version:}

A. Paula Paula Marinho Reis, M. Cave, A. J Sousa, J. Wragg, M. Rangel, et al.. Lead and zinc concentrations in household dust and toenails of the residents (Estarreja, Portugal): a sourcepathway-fate model. Environmental Science: Processes \& Impacts, 2018, 20 (9), pp.1210-1224. 10.1039/c8em00211h . hal-01966568

\section{HAL Id: hal-01966568 https://hal.science/hal-01966568}

Submitted on 5 Apr 2019

HAL is a multi-disciplinary open access archive for the deposit and dissemination of scientific research documents, whether they are published or not. The documents may come from teaching and research institutions in France or abroad, or from public or private research centers.
L'archive ouverte pluridisciplinaire HAL, est destinée au dépôt et à la diffusion de documents scientifiques de niveau recherche, publiés ou non, émanant des établissements d'enseignement et de recherche français ou étrangers, des laboratoires publics ou privés. 


\title{
Lead and zinc concentrations in household dust and toenails of the residents (Estarreja, Portugal): a source-pathway-fate model $\uparrow$
}

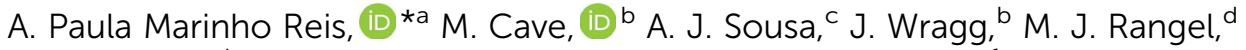 \\ A. R. Oliveira, ${ }^{d}$ C. Patinha, ${ }^{a}$ F. Rocha, ${ }^{a}$ T. Orsiere ${ }^{e}$ and Y. Noack ${ }^{\dagger}$
}

This paper describes a methodology developed to assess and apportion probable indoor and outdoor sources of potentially toxic elements while identifying chemical signatures in the household dust collected from private homes in an industrial city (Estarreja, central Portugal). Oral bioaccessibility estimates and the chemical composition of toenail clippings were used to assess indoor dust ingestion as a potential exposure pathway and further investigate exposure-biomarker relationships. Indoor and paired outdoor dust samples were collected from each household. A total of 30 individuals, who provided toenail clippings and a self-reported questionnaire, were recruited for the study. Total concentrations of 34 elements, including lead and zinc, were determined in washed toenail samples and household dust via Inductively Coupled Plasma-Mass Spectrometry. The oral bioaccessibility was estimated using the Unified BARGE Method. The enrichment factor shows that lead was enriched $(10<$ $E F<100)$ while zinc $(E F>100)$ was anomalously enriched in the household dust, thus indicating potential exposure in the home environment. The results from principal component analysis coupled to cluster analysis and linear discriminant analysis suggested that mixed contamination derived from multiple sources with a predominance of biomass burning. Stepwise multiple linear regression analysis was performed to model toenail data using the indoor dust elemental composition. Whereas the model obtained for lead was not reliable, indoor dust zinc and antimony contents arose as good predictors of toenail zinc. The exposure-biomarker relationships seem to be influenced by the oral bioaccessibility of the elements.

\section{Environmental significance}

Indoor dust can pose serious risks to human health, as evidenced by an increasing number of associations being reported between air particulates and adverse health outcomes. Metals and metalloids in indoor dust are considered to be a primary concern of exposure because of their known toxicity, persistence and nondegradability and ability to accumulate in the tissues and internal organs of the human body. Recent studies carried out in the industrial city of Estarreja reported on elevated contents of lead and zinc, among other potentially toxic elements, in natural media such as soil and groundwater. Information on residential contamination is however almost null. This paper describes a study carried out to fill this knowledge gap. Updated methodologies are used to obtain a source-pathway-fate model for environmental lead and zinc. The potential for human exposure to these potentially toxic elements in the household dust is discussed taking into account their oral bioaccessibility and contents determined on the residents' toenails.

${ }^{a}$ GEOВIOTEC, Departmento de Geociências, Universidade de Aveiro, Campus Universitário de Santiago, 3810-193 Aveiro, Portugal. E-mail: pmarinho@ua.pt

${ }^{b}$ British Geological Survey, Keyworth, Nottingham, NG12 5GG, UK

'CERENA, DECivil, Instituto Superior Técnico. Universidade de Lisboa, Portugal

${ }^{d}$ Departmento de Geociências, Universidade de Aveiro, Campus Universitário de Santiago, 3810-193 Aveiro, Portugal

${ }^{e}$ Aix Marseille Université, Avignon Université, CNRS, IRD, IMBE, Equipe Biomarqueurs Environnement Santé, Faculté de Médecine, Marseille, France

${ }^{f}$ Aix Marseille Université, CNRS, IRD, INRA, Coll France, CEREGE, Aix-en-Provence, France

\section{Introduction}

Time people spend indoors is influenced by several factors, like gender, occupation, and age. People tend to spend between $85 \%$ and $90 \%$ of their time exposed to the indoor rather than the outdoor atmosphere. ${ }^{1}$ Understandably, interest in indoor dust chemistry and variations of chemical compositions between indoor and outdoor environments comes mainly from the fact that humans spend most of their time indoors. Furthermore, an increasing number of associations are being reported between air particulates and a broad number of adverse health outcomes. $^{2}$ There is, therefore, a necessity to identify and 
characterise the hazards associated with indoor dust to develop ways of reducing the associated risks and make our homes safer.

While a large body of literature is devoted to suspended particulate matter in the indoor environment, ${ }^{3-7}$ to date, fewer studies have focused on the characterisation of indoor dust deposited in the floor from residential homes, which is commonly designated as household dust.8,9 However, incidental ingestion of household dust is an important non-dietary pathway for some hazardous substances leading to potential health risks, especially for children. ${ }^{\mathbf{1 0}}$

It is long known that long-term exposure to environmental lead $(\mathrm{Pb})$ exerts neurotoxic effects on human health. ${ }^{11,12}$ Recent studies have found negative health effects even after low dose exposures to this trace element. ${ }^{\mathbf{1 1} 13} \mathrm{Zinc}(\mathrm{Zn})$ is an essential nutrient and, similarly to $\mathrm{Pb}$, it is ubiquitous in the environment. Although $\mathrm{Zn}$ is not involved in cellular redox cycle and has traditionally been regarded as relatively nontoxic, studies increasingly show that $\mathrm{Zn}^{2+}$ is a potent killer of neurons, glia, and other cell types. ${ }^{14,15}$ In contrast to $\mathrm{Pb},{ }^{16,17}$ the behaviour of $\mathrm{Zn}$ in household dust has received little attention to date, and knowledge is scarce about $\mathrm{Zn}$ sources and pathways in the residential dust.

Although whole blood lead level is regarded as the most representative indicator of the current environmental and body lead status, ${ }^{18,19}$ the collection of blood samples, especially from young children, is not always feasible due to its invasive character and the requirement for parental consent. In recent years, trace element analyses of keratinized matrices like hair ${ }^{20}$ or nails ${ }^{21}$ have consistently increased, in addition to the common use of blood and urine. ${ }^{19,22}$ Increasing evidence supports that nail, particularly toenail, concentrations of most trace elements are useful biomarkers of exposure in which a single sample is assumed to represent long-term exposure. ${ }^{23,24}$

While there is a reasonable amount of literature available on the identification of sources, especially outdoors, ${ }^{25-28}$ studies that have examined the source apportionment of indoor residential contaminants are still scarce. ${ }^{29} \mathrm{~A}$ few studies on indoor residential environments have examined indicators specific to indoor sources, such as wood burning in fireplaces, ${ }^{30}$ and cooking. ${ }^{31,32}$ Urban studies on the composition of street dust have identified elemental tracers and source signatures typically associated with primary urban $\operatorname{sources}^{33,34}$ (e.g., vehicular traffic, waste incineration). Potentially toxic elements (PTEs), such as $\mathrm{Pb}$ and $\mathrm{Zn}$, introduced into the environment through different sources, find their way into residential homes either as airborne dust or through items used or activities carried out within the house.

Distinguishing between anthropogenic and naturally occurring PTEs concentrations is intrinsically difficult and the main focus of this investigation. Multivariate statistical analysis used for identification and source apportionment offer some advantages relative to other techniques, such as stable isotopes, including that of the interest from environmental assessors in empirical methodologies applicable to a broad range of environmental scenarios. Multivariate techniques evaluate multiple chemicals and allow the development of a site-specific chemical profile that has been referred to as a signature..$^{35}$ Multivariate chemical signatures have been used to identify contaminated sites and sources of hazardous substances through techniques such as principal components analysis ${ }^{27,36}$ and multiple correspondence analysis. ${ }^{37}$ Cluster analysis (CA) is often coupled to principal components analysis (PCA) to check results and to provide groups of individual samples and variables. There are several examples of application to environmental sciences available from the literature..$^{\mathbf{3 8 - 4 0}}$ We propose an approach that combines PCA with CA and linear discriminant analysis (LDA) to identify chemical signatures in household dust samples and further assess indoor and outdoor sources of PTEs. The LDA was applied to check whether the clusters obtained from CA were statistically significant and if the chemical signatures significantly discriminated between the clusters.

This paper follows on from earlier research undertaken to assess indoor dust ingestion as a potential exposure pathway in the home environment and further investigates the exposurebiomarker relationships. ${ }^{30}$ Elevated household dust $\mathrm{Zn}$ contents and a few anomalous toenails $\mathrm{Pb}$ concentrations justified additional investigation on these two PTEs. Hence, the main aims of this study were: (i) to determine $\mathrm{Pb}$ and $\mathrm{Zn}$ concentrations in the household dust and residents' toenails; (ii) to develop a methodology to identify potential sources of PTEs in the household dust and estimate their relative contributions and (iii) to investigate exposure-biomarker relationships for the two PTEs. With this study, we further aimed to assess the effectiveness of the developed methodology to achieve reliable source-pathway-receptor models.

\section{Material and methods}

\subsection{The study area}

Estarreja is a coastal municipality located in the centre of Portugal that extends over an area of $108.2 \mathrm{~km}^{2}$ and has an estimated resident population of 26555 inhabitants. The map locating the city in the Portuguese territory is presented in the form of ESI (Fig. S1 $\dagger$ ). Urban, peri-urban and rural areas coexist within the municipality, on a $3: 4: 3$ ratios. In terms of landuse, it is roughly distributed amongst agricultural land (54\%), urban and peri-urban areas (18\%) and forest land $(27 \%) .{ }^{41}$ The climate is Mediterranean temperate (type Csb according to the Köppen-Geiger climate classification system), characterised by dry and warm summers, with average annual temperatures of $14.9{ }^{\circ} \mathrm{C}$ and an average annual rainfall of $1048 \mathrm{~mm}$. Main wind directions are $\mathrm{N}-\mathrm{NW}$, driven by humid tropical air masses moving to the east, especially in the summer, and E-SE during winter. ${ }^{42}$

The municipality encompasses one of the most important industrial complexes of the country, known as the chemical complex of Estarreja (CCE). Since the 1950s, the complex has produced a variety of organic and inorganic compounds, such as nitric acid, aniline, nitrobenzene, chlorate compounds from rock salt, polyurethanes and others. ${ }^{34,42}$ In the early years, sulphide ores were used in fertiliser production, which was one of the primary activities of the CCE, yet one of the most polluting for PTEs such as arsenic (As) and Pb. In the late 1990's 
the area was remediated and industrial wastes containing hazardous materials such as pyrite ashes, mercury-enriched muds, and organochlorine compounds, were buried and sealed near the complex. Nevertheless, recent studies have been reporting on elevated contents of environmental contaminants in natural media, namely mercury $(\mathrm{Hg})$ in lake sediments, ${ }^{43}$ As in soil and groundwater, ${ }^{\mathbf{4 4 , 4 5}}$ and PM10 in ambient air. ${ }^{\mathbf{4 2}}$ In recent years, several studies available from the literature have suggested that currently, vehicular traffic stands for a contributor of increasing importance to the quality degradation of the local environment. ${ }^{42,46}$ Hot-dip galvanising for zinc coating or the production and assembly of carbon steel, stainless steel, and aluminium tubing are industrial processes taking place in the CCE likely to emit PTEs to the atmosphere. Indeed, the $\mathrm{Zn}$ concentrations reported in different studies focusing on groundwater, soils, home-grown foodstuffs and street dust ${ }^{\mathbf{3 4 , 4 4 , 4 5}}$ suggest elevated levels of environmental $\mathrm{Zn}$ in the region.

Data available for the study area from the QualAr database, the Portuguese online database for air quality monitoring, ${ }^{47}$ show that during sample collection, only $\mathrm{PM}_{10}$ levels (daily average) were occasionally above the $50 \mu \mathrm{g} \mathrm{m}^{-3}$ limit value established by the European Commission (EC) 2008/50 Framework Directive for air quality parameters and pollutants. Other monitored air pollutants such as $\mathrm{SO}_{2}$ and $\mathrm{NO}_{2}$ were below the legislated limits.

\subsection{The study group}

2.2.1 Toenails collection. Inclusion criteria were the compliance of the residents to participate in the study, and the geographical location of the households. The goal was to obtain sampling sites evenly distributed across the study area. Furthermore, we were also interested in recruiting family members of different age and gender living in the same home, whenever possible.

A total of 30 individuals from 21 households were recruited for the study through informal interviews: 19 households corresponding to 27 individuals living in Estarreja forming the study group, plus 2 households and 3 residents from residential areas with no anticipated environmental contaminants who were used for comparison. On recruitment, the participants were informed about the aims of the study. The protocol was carefully explained and written consent was obtained before sampling. The National Committee for Data Protection granted ethical approval to the study (Proc. no. 1241/2013).

Residents were asked to allow toenails to grow for at least 2 weeks prior to sample collection. Toenail clippings were collected with a stainless-steel clipper from all 10 toes by the participants themselves and stored in a polyethene container provided on recruitment. Clippings without adequate toenail growth $(n=1)$ or having traces of nail polish $(n=1)$ were excluded from the study.

2.2.2 Measurement of other covariates. Age, gender, education level, profession and smoking status were reported by the participants through a self-administered questionnaire. The smoking status was classified into two groups: presence or absence of smokers in the household. Age was also categorised into two groups: adults and children ( $<18$ years old). Other lifestyle factors used as covariates included home-grown vegetables and home-reared poultry consumption, irrigation water, drinking water habits, and cooking-showering-washing water. The characteristics of the physical environment of the homes included the type of heating system, the area and age of the house, the number of years since the last interior and exterior wall painting, the occurrence of reparation works ( $<1$ year), and the existence of garden and/or backyard. Further details on the questionnaire data are available from an earlier study. ${ }^{30}$

\subsection{Household dust sampling}

In this study, the term household dust encompasses dust samples collected from indoor and outdoor areas of the house (henceforth identified as indoor dust and outdoor dust, respectively). Although indoor dust ingestion was the exposure pathway of interest, both indoor and outdoor areas were sampled to assess differences in the geochemistry of the paired dust samples, which can provide relevant information for a better understanding of sources, mobility, and fate of the PTEs.

Participants were asked to abstain from cleaning floor surfaces for a period of 7 days before the scheduled house dust sampling. A composite indoor dust sample was collected in each home using a vacuum sampler as earlier described. ${ }^{30}$ Outdoor dust was collected from different areas outside the house such as patios, garden paths and driveways, using a small dust pan and a broom. Fig. S1 $\dagger$ shows the location of the sampling sites in the study area.

The $<150 \mu \mathrm{m}$ particle size fraction of the dust was obtained by dry sieving. Although the $<250 \mu \mathrm{m}$ particle size fraction is usually recommended for the ingestion route, ${ }^{48}$ recent studies have been indicating that above $150 \mu \mathrm{m}$ the indoor dust is composed mainly of exterior soil. ${ }^{49}$ Hence, the $<150 \mu \mathrm{m}$ particle size fraction was selected to minimise the contribution of exterior soil to the indoor dust composition.

\subsection{Instrumentation}

Dust samples were digested with aqua regia at $90{ }^{\circ} \mathrm{C}$ in a microprocessor controlled digestion block for $2 \mathrm{~h}$, and the analysis of 34 chemical elements, including $\mathrm{Pb}$ and $\mathrm{Zn}$, was carried out by Inductively Coupled Plasma-Mass Spectrometry (ICP-MS) at ACTLABS Analytical Laboratory, Canada. Each sample batch prepared for ICP-MS analysis included dust samples, duplicates, blanks and standard reference materials, for quality assurance and quality control (QC/QA) procedures. The standard reference materials GRX-1, GRX-4, GRX-6 and SAR-M (United States Geological Survey) were selected to represent a wide range of total elemental concentrations. Results of method blanks were always below detection limits, which are of $0.01 \mathrm{mg} \mathrm{kg}^{-1}$ for $\mathrm{Pb}$ and $0.1 \mathrm{mg} \mathrm{kg}^{-1}$ for $\mathrm{Zn}$. Values for precision (expressed as the relative standard deviation RSD\%) were typically less than $15 \%$ for all elements.

The bioaccessibility of the PTEs was determined by subjecting a subset of indoor dust samples $(n=8)$ to the Unified BARGE Method (UBM), as described elsewhere. ${ }^{30}$ For quality 
control purposes, duplicate samples, blanks, and the bioaccessibility guidance material BGS 102 were extracted with every batch of the UBM extractions. The blanks always returned results that were below the detection limit. For the subset under study, the RSD in the stomach phase was $2.5 \%$ for $\mathrm{Pb}$ and $6.5 \%$ for $\mathrm{Zn}$, while in the intestine phase was $55.4 \%$ and $32.5 \%$ for $\mathrm{Pb}$ and $\mathrm{Zn}$, respectively. Hence, only data obtained from the stomach phase were used to assess the PTEs' bioavailability from their bioaccessibility. ${ }^{\mathbf{5 0}}$

Toenail samples were washed thoroughly, rinsed repeatedly in Milli-Q water (Millipore Corp., Billerica, Mass.) and methanol, dried, weighed and stored in polyethylene containers. Concentrations of $\mathrm{Pb}, \mathrm{Zn}$, and 32 other elements were determined in the toenail clippings as earlier described. ${ }^{30} \mathrm{QA} / \mathrm{QC}$ procedures included method reagent blanks and a standard reference material (NIST SRM 1575a). This reference material is intended primarily for use in the evaluation of techniques employed in the analysis of pine needles and materials of a similar matrix. Recoveries obtained in the SRM were always equal to $83 \%$ for $\mathrm{Pb}$, and varied between 101 and $102 \%$ for $\mathrm{Zn}$, within acceptable ranges. Mean repeatability (expressed as $\mathrm{RSD} \%$ ) was 12.4 for $\mathrm{Pb}$ and 0.8 for $\mathrm{Zn}$.

\subsection{Statistical techniques}

Univariate and bivariate statistics, as well as distribution plots, were examined for all variables. Non-parametric tests were used to assess differences in dust metal concentrations between indoor and outdoor house locations. Differences between groups were tested using the Mann-Whitney $U$, being the results interpreted based either on rank differences or group median differences. A probability of 0.05 or lower was regarded as significant in testing the null hypothesis of no differences in concentrations across the home environments.

Boxplots and the Shapiro-Wilk test were used to check whether the variables under study had a normal distribution. The results indicated that most variables were not normally distributed, within a 95\% significance level. Hence, the chemical data were log-transformed prior to the multivariate analysis.

Data patterns were investigated through multivariate analysis of the data matrix comprising the full suite of chemical elements determined in the household dust. The factorial analysis aimed to assess potential differences between the chemistry of indoor and outdoor dust samples. It further aimed at identifying and characterising potential sources, as well as quantifying their relative contribution to the total PTE dust content. A combination of different techniques of multivariate analysis was used to achieve the desired purposes, as described henceforth. For clarity, a flow diagram summarising the statistical methodology developed is presented in the form of ESI (Fig. S2†).

The PCA technique is one of the multivariate analyses that have been successfully applied for source identification. ${ }^{6,27,51}$ PCA is adapted to quantitative variables, which transforms $u$ possibly correlated variables into $u$ uncorrelated variables, referred to as principal components. ${ }^{52}$ PCA proposes to explain the maximum amount of variance with the fewest number of principal components (PCs) and minimum loss of relevant information. The relationships between the geochemical variables can be identified by projecting in 2-D plots the correlation of each original variable with the first, and more important, PCs (loading plots). Variables used to calculate the PCs are named active variables. Additional variables usually referred to as supplementary variables, can also be represented in the biplots. Although supplementary variables are not used to obtain the PCs, their geometrical relationships with the active variables can be observed in the $2 \mathrm{D}$ plots, ${ }^{\mathbf{5 3 , 5 4}}$ providing further support to the interpretation of the results.

Following PCA, MLR analysis was applied using the PTEs logtransformed total concentration determined in the dust as the dependent variables and factor scores (PCs) as the independent variables, to predict the contribution of each source to the household dust pollution. Using eqn (1) the source's contribution to the total PTE content in the household dust can be apportioned. The contribution of each identified source was calculated as follows: ${ }^{55,56}$

$$
S_{\mathrm{i}}=\left(\frac{\beta_{\mathrm{i}}}{\sum \beta_{\mathrm{i}}}\right) \times 100
$$

where $S_{\mathrm{i}}$ is the source contribution to the total dust PTE content, $\beta_{\mathrm{i}}$ is the standardized regression coefficient for the identified source (available from the MLR coefficient table) and $\Sigma \beta_{\mathrm{i}}$. is the sum of the standardized regression coefficients.

Cluster analysis (CA) is part of the sequence of techniques starting with PCA and finishing with LDA. First, the PCA reduces the dimensions and therefore the number of variables, which makes it easier to run the CA. Then, CA identifies the grouping and, lastly, the LDA checks the goodness-of-fit of the model derived from the cluster analysis and profiles the clusters. The LDA allows the identification of a few linear combinations of the original variables that serve to discriminate among clusters. ${ }^{57}$ The CA depends on the LDA to check whether the groups are statistically significant and the variables significantly discriminate between the groups. Furthermore, the LDA builds a predictive model that allows predicting the cluster membership. Thus, the clusters obtained from the CA were used in the LDA to assess the prevalent sources of PTEs, both to indoor and outdoor dust samples.

In this study, the multiple linear regression (MLR) technique was utilised twice, for different purposes. The first MLR analysis was used to predict the contribution of each metal source to the household pollution, as described earlier. Residuals plots were used to assess whether residuals were approximately normally distributed. The second MLR was performed stepwise to model the relationships between toenail data and PTE contents in the household dust samples. In this stepwise MLR, concentrations of PTEs in the toenails were used individually as the dependent variable to obtain the MLR models. The criteria for stepwise MLR were: probability of $F$ to enter $\leq 0.05$ and probability of $F$ to remove $\geq 0.1$. The Durbin-Watson test assured the absence of first-order linear auto-correlation in our multiple linear regression data, that is, that we had an independence of 
observations, which is one of the assumptions required for MLR to give us a valid result.

Univariate and bivariate statistics, boxplots, the ShapiroWilk and the Mann-Whitney $U$ tests, CA, LDA and MLR analysis were performed using the IBM SPSS (v. 21) software. The PCA was performed using the AnDad (v. 7.12) free software package.

\section{Results and discussion}

\subsection{Lead and zinc in toenails}

Total $\mathrm{Pb}$ concentration in toenails of the study group ranged from 60 to $2770 \mu \mathrm{g} \mathrm{kg}^{-1}$ with an average value of $440 \mu \mathrm{g} \mathrm{kg}$ (Table 1). Higher concentrations were obtained for $\mathrm{Zn}$ that range from 72 to $191 \mathrm{mg} \mathrm{kg}^{-1}$ and have an average of $120 \mathrm{mg}$ $\mathrm{kg}^{-1}$. Mean concentration values of the study group relative to the controls are lower for $\mathrm{Pb}$ and higher for $\mathrm{Zn}$. However, the differences are not statistically significant $(p>0.05)$.

On average, toenail $\mathrm{Pb}$ contents obtained in this study are lower than the ones reported for populations exposed to mining contamination, ${ }^{\mathbf{2 0 , 2 1}}$ and slightly higher than those found in workers exposed to welding fumes. ${ }^{58}$ In contrast, the majority of the participants have $\mathrm{Zn}$ contents in their toenails that are higher than those found in other populations exposed to environmental contaminants. ${ }^{21}$ Goulle et al. 2009 propose reference ranges, ${ }^{23}$ derived from concentrations determined in toenail samples from 50 healthy volunteers, of $63-105 \mathrm{mg} \mathrm{kg}^{-1}$ for $\mathrm{Zn}$ and $70-1800 \mu \mathrm{g} \mathrm{kg}^{-1}$ for $\mathrm{Pb}$, that are slightly lower than the ranges found for the volunteers of this study.

Levels of $\mathrm{Pb}$ in the toenails do not seem to be dependent upon the age or gender of the study participants (Fig. 1). Of note, the several outlier values observed for $\mathrm{Pb}$ in adults (Fig. 1C) that supported the decision to further investigate human exposure to this PTE in the area. The content of $\mathrm{Zn}$ in children's toenails (Fig. 1D) is significantly higher than in adults $(p<0.05)$. The result is not unexpected given that growing infants, children and growing adolescents require more $\mathrm{Zn}$ per $\mathrm{kg}$ of body weight than do mature adults. ${ }^{15}$ Although $\mathrm{Zn}$ is an essential nutrient for normal growth because of its critical role in multiple metabolic pathways, there is no storage form of $\mathrm{Zn}$ in the body that can be readily mobilised when intakes are

Table 1 Total concentrations of $\mathrm{Pb}\left(\mu \mathrm{g} \mathrm{kg}^{-1}\right)$ and $\mathrm{Zn}\left(\mathrm{mg} \mathrm{kg}^{-1}\right)$ in toenails of the study $(n=27)$ and control $(n=3)$ groups; comparison with other relevant studies

\begin{tabular}{lll}
\hline & $\mathrm{Pb}$ & $\mathrm{Zn}$ \\
\hline Min & 60 & 72 \\
Max & 2770 & 191 \\
Mean \pm SD & $404 \pm 634$ & $120 \pm 30$ \\
Median & 190 & 116 \\
Non-exposed group & ${ }^{b} 90$ & ${ }^{c} 139$ \\
Coelho et al. 2012 (ref. 20) & ${ }^{a} 1110 \pm 340$ & - \\
Grashow et al. 2014 (ref. 58) & ${ }^{a} 390 \pm 3000$ & - \\
Goullé et al. 2009 (ref. 23) & ${ }^{c} 460$ & ${ }^{c} 83$ \\
Ndilila et al. 2014 (ref. 21) & ${ }^{b} 21400$ & ${ }^{b} 113$
\end{tabular}

Min: minimum; Max: maximum; SD: standard deviation. ${ }^{a}$ Mean $\pm \mathrm{SD}$. ${ }^{b}$ Mean. ${ }^{c}$ Median. inadequate,$^{59}$ enhancing the need for a regular dietary supply. The results obtained show that $\mathrm{Zn}$ deficiency is not a health issue for the study group.

In summary, on average, $\mathrm{Zn}$ contents in the toenails of the study group are more elevated than those reported in other studies and above the reference range ${ }^{23}$ (Table 1). Several outlier values were observed for $\mathrm{Pb}$ in adults.

\subsection{Total and bioaccessible concentrations of $\mathrm{Pb}$ and $\mathrm{Zn}$ in household dust samples}

Differences in $\mathrm{Pb}$ and $\mathrm{Zn}$ household dust contents were assessed through their concentrations ratio in the indoor and outdoor dust (Table 2), calculated as follows:

ratio $_{\mathrm{i}}=$

median concentration of element $i$ in indoor dust samples median concentration of element $\mathrm{i}$ in outdoor dust samples .

While concentration information is useful for direct comparisons of indoor dust with outdoor media, loading is considered to be an appropriate index of potential exposure, ${ }^{60}$ which is understandably the reason why it is the measure most widely used in epidemiological studies. Studies that aim assessing differences between the chemical composition of indoor dust and exterior soil or dust are more limited. There are, however, some studies that can be used for comparison, and Table 2 shows ratios estimated from data found in the literature for the cities of Ottawa in Canada, ${ }^{8}$ Aswan in Egypt ${ }^{61}$ and Muscat in Oman. ${ }^{9}$ The table further shows some summary statistics for PTEs concentrations in the indoor dust collected from the Estarreja residences as well as in the area with no anticipated pollution. Statistics for outdoor metal concentrations are provided in the form of ESI (Table S1 $\dagger$ ).

In Estarreja, the concentrations of $\mathrm{Pb}$ and $\mathrm{Zn}$ are almost two times higher in indoor dust than in outdoor dust samples. However, differences in concentrations are statistically significant only for $\mathrm{Zn}(U=106, p=0.019)$. Also significant is the higher $\mathrm{Zn}$ content in outdoor dust samples collected from the area with no anticipated pollution, but the number of samples available is not enough to make assumptions about local outdoor sources. The comparison with other studies available from the literature discloses distinct distribution patterns. Some ${ }^{\mathbf{8}, 61}$ report on higher indoor metal concentrations (ratio > 1), which is in agreement with our results (Table 2). It is of note that, although the calculated ratio is smaller than the ones reported for Ottawa and Aswan, in Estarreja the dust Zn contents are more elevated both in indoor and outdoor dust samples (Tables 2 and S1 $\dagger$ ). Rashed (2008) found an inverse tendency, with lower $\mathrm{Pb}$ contents in indoor dust samples (ratio $<1$ ) from Aswan (Table 2).

A subset of dust samples $(n=8)$ was subjected to the UBM to estimate the oral bioaccessibility of the PTEs in the indoor dust. The bioaccessible fraction (BAF) was calculated as follows:

$$
\mathrm{BAF}=\frac{\mathrm{UBM} \text { extracted concentration in the stomach }}{\text { total concentration in the indoor dust }}
$$



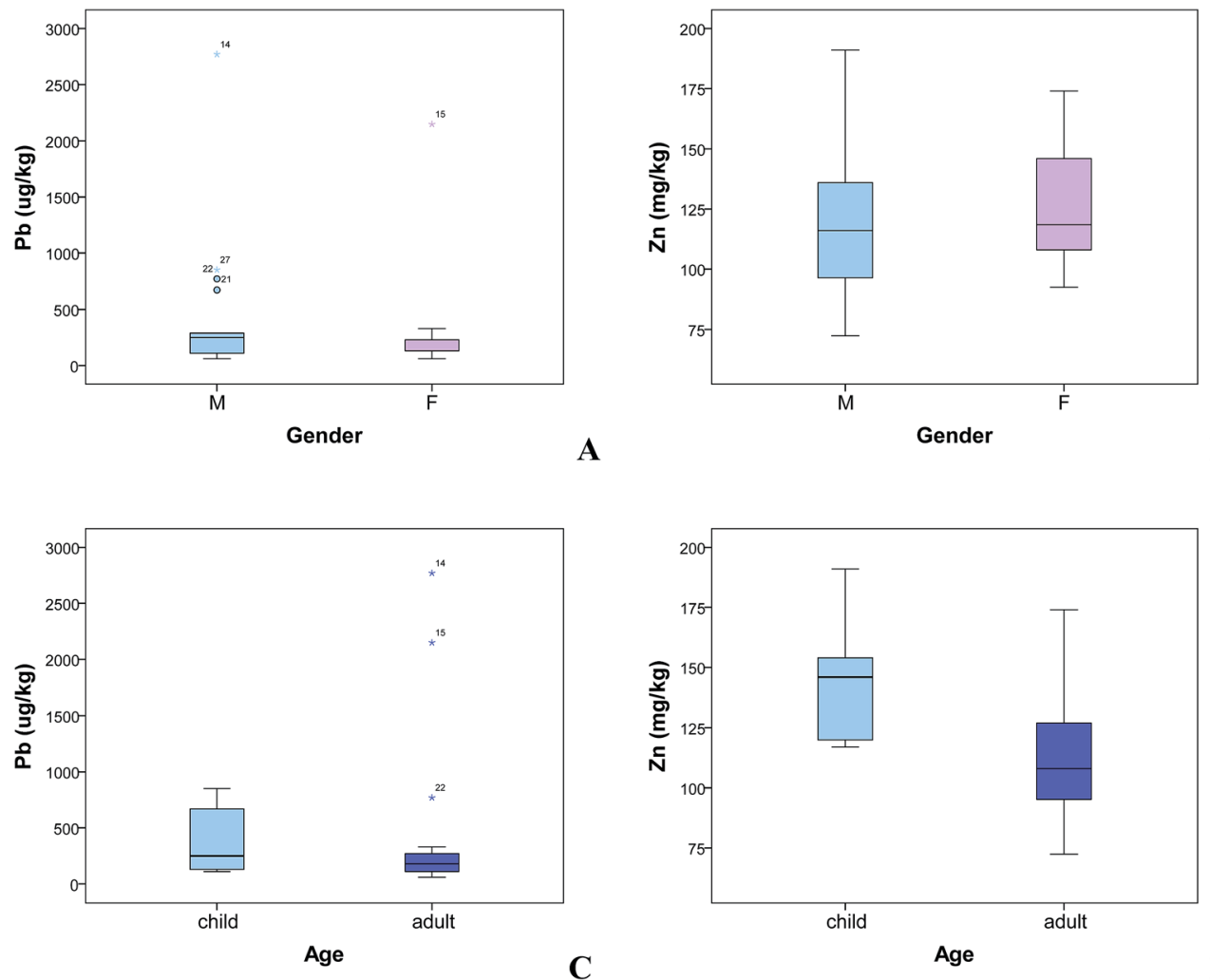

Fig. 1 Box-plots displaying the distribution of $\mathrm{Pb}$ (plots A and C) and $\mathrm{Zn}$ (plots B and D) contents in toenails according to gender (plots A and B) and age group ( $C$ and $D$ ).

The oral bioaccessibility estimates are provided in the form of ESI (Table S2 $\dagger$ ). Following ingestion, about $60 \%$ of $\mathrm{Pb}$ and $84 \%$ of $\mathrm{Zn}$ indoor dust total contents were estimated to be bioaccessible to the residents (Table $\mathrm{S} 2 \dagger$ ). The standard-deviation values indicate that the $\mathrm{BAF}$ of $\mathrm{Pb}$ varies more than that of $\mathrm{Zn}$, suggesting that the bioaccessibility of $\mathrm{Pb}$ is highly sitespecific and controlled by the particular physicochemical properties of the indoor dust. Zinc has BAF values in the 80$90 \%$ range for the majority of the studied samples, suggesting that, in this study, the total concentrations may be representative of the element's bioavailability for a worst-case-scenario.

At their homes, people spend long periods of time indoors, which in case of a long-term exposure scenario increases the health risk. Although it is well established that ingestion represents a major exposure route for contaminants in comparison to inhalation or dermal absorption, ${ }^{62-64}$ indoor dust ingestion is often an overlooked exposure pathway for PTEs. The data show that the indoor dust has more elevated concentrations of $\mathrm{Pb}$ and $\mathrm{Zn}$, especially the latter. Hence, assessing potential indoor and outdoor sources controlling the composition of the indoor dust has the potential to increase understanding of this exposure pathway.

\subsection{Source identification and apportionment}

Enrichment factors (EFs) have been widely used to distinguish between anthropogenic influences and natural background

Table 2 Summary statistics of $\mathrm{Pb}$ and $\mathrm{Zn}$ concentrations $\left(\mathrm{mg} \mathrm{kg}^{-1}\right)$ in indoor dust samples $(n=19)$ and the ratio between indoor and outdoor concentrations; comparison with other studies

\begin{tabular}{|c|c|c|c|c|}
\hline Element & Ratio & Mean & Range & Reference \\
\hline $\mathrm{Pb}$ & 1.6 & 174 & $53-1180$ & This study \\
\hline $\mathrm{Zn}$ & 1.9 & 1349 & $582-5210$ & \\
\hline $\mathrm{Zn}$ & 0.4 & 853 & $839-867$ & \\
\hline $\mathrm{Pb}$ & 6.7 & 406 & $50-3226$ & Rasmussen et al. 2001 (ref. 8) \\
\hline $\mathrm{Zn}$ & 6.4 & 717 & 239-1840 & \\
\hline $\mathrm{Pb}$ & 0.6 & 102 & $85-120$ & Rashed 2008 (ref. 61) \\
\hline
\end{tabular}


contents, ${ }^{6,65,66}$ despite the intrinsic shortcomings associated with factors such as the variable composition of the local substrate or the impact of biogeochemical processes. ${ }^{67}$ In this study, the EFs were used as screening tool to ascertain relevant PTEs to be included in the source apportionment study. EFs > 10 are usually deemed indicators of a non-crustal source for the elements (unnaturally enriched in the sample media), while elements of crustal origin have EFs $<10$ (natural geochemical background). Li et al. (2016) further specify that an EF $>100$ indicates an anomalous enrichment of the element in the sampled media. ${ }^{66}$

In this study, EF values were calculated with respect to aluminium (Al), according to:

$$
\mathrm{EF}=\frac{\left(\frac{C_{\mathrm{X}}}{C_{\mathrm{Ref}}}\right)_{\text {dust }}}{\left(\frac{C_{\mathrm{X}}}{C_{\mathrm{Ref}}}\right)_{\text {crust }}}
$$

where $\left(C_{\mathrm{X}} / C_{\mathrm{Ref}}\right)_{\text {dust }}$ and $\left(C_{\mathrm{X}} / C_{\mathrm{Ref}}\right)_{\text {crust }}$ were the concentration ratios of the element of interest to the reference element $\mathrm{Al}$ in the samples and in the continental crust, ${ }^{68}$ respectively. Among the elements potentially related to the earth continental crust, Al was selected to be reference element because it showed higher concentrations in the outdoor dust than in paired indoor samples. Others, such as potassium $(\mathrm{K})$ or magnesium $(\mathrm{Mg})$, had higher indoor concentrations, which could be indicative of indoor sources, and weren't therefore considered. The results obtained are graphically displayed and presented in the form of ESI (Fig.S3†). While elements such as boron (B), bismuth (Bi), calcium (Ca), copper (Cu), As, selenium (Se), molybdenum (Mo), cadmium (Cd), tin (Sn), tungsten (W), $\mathrm{Pb}$, and $\mathrm{Hg}$ are enriched $(10<\mathrm{EF}<100)$, Zn and antimony $(\mathrm{Sb})$ are anomalously enriched in the household dust ( $\mathrm{EF}>100)$.

Principal components analysis was performed to identify elemental associations (chemical signatures) suitable to be used as chemical tracers of distinct pollutant sources. Given the excessive amount of chemical elements $(u=53)$ to the number of samples $(n=38)$ available from the dataset, it was necessary to exclude some variables from the PCA analysis. Thus, elements having an $\mathrm{EF}>10$ were used as active variables to run the PCA, while those having an EF $<10$ remained as supplementary variables. To get a good understanding of the geometric relationships between the variables, Fig. 2 presents the loading plots of the PCA. The eigenvalues, the explained variances and variables loadings of the first four PCs, which have an eigenvalue above 1 and account for $c a$. 74\% of the total variance, are provided in the form of ESI (Table S3†). Since knowing the variation patterns between indoor and outdoor samples may be useful for data interpretation, boxplots of elemental concentrations in the household dust are further provided as ESI (Fig. S4†).

PC1 (accounting for $42.8 \%$ of the total variance) clearly separates As from the majority of the elements under study (Fig. 2A). While As shows significantly higher concentrations in the outdoor dust $(p<0.05)$, other PTEs associated with PC1 have significantly higher concentrations in indoor dust samples
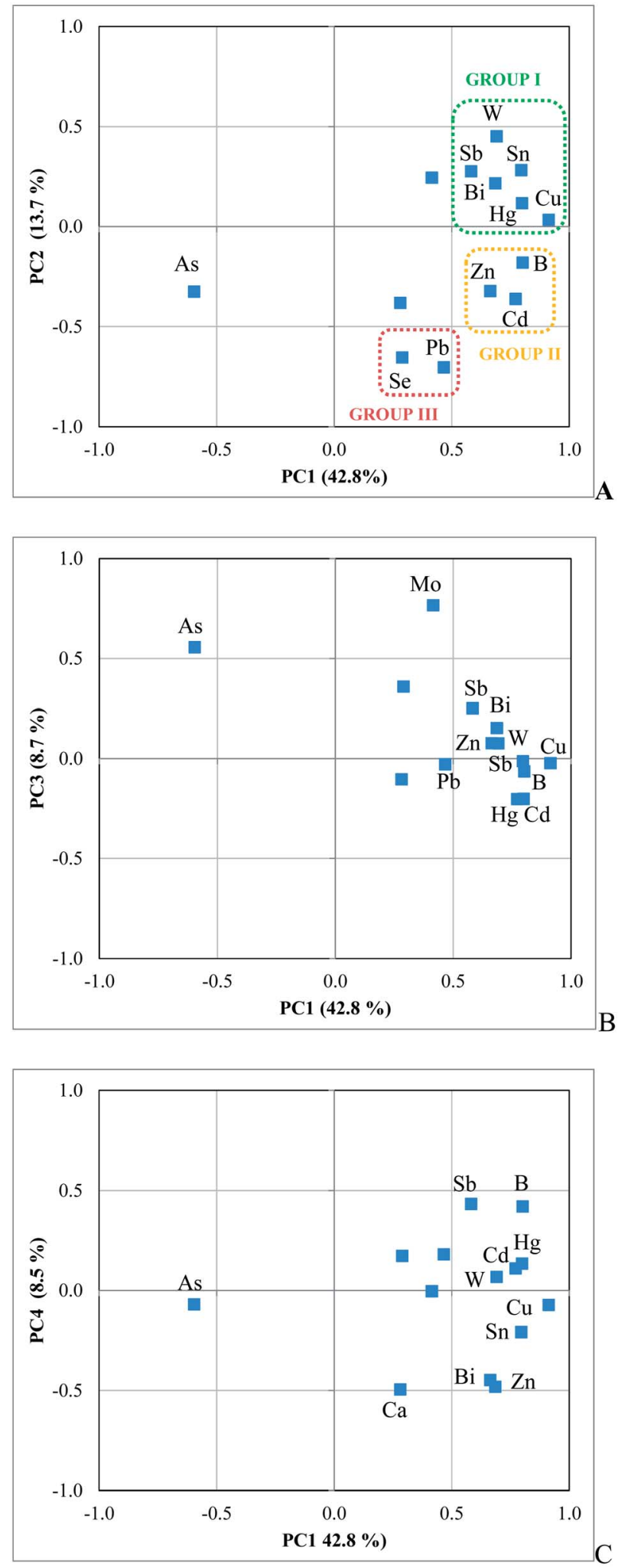

Fig. 2 Loadings plots for the four PCs (three factorial planes) under study. Only variables well represented in each of the investigated factorial planes (loadings > 0.5) were labelled; unlabelled variables were considered irrelevant to the interpretation of the geometrical relationships. 
(Fig. S4 $\dagger$ ). Supplementary variables such as scandium (Sc), thorium (Th), manganese (Mn), and yttrium (Y) have, on PC1, loadings similar to those of As (Table S3†), suggesting a relationship between these variables. Thus, although As has an EF $=25$ indicative of a non-crustal source (Fig. S3†), its association with elements such as $\mathrm{Mn}$, Th, and Y suggests that an earth crust related source is more likely than an anthropogenic origin. Elements such as Mn, Y, lanthanum (La), Th, or gallium (Ga) in dust have been identified as natural elements in several studies, ${ }^{30,69,70}$ which supports further the assumption that As in the household dust of Estarreja has a natural source. The large number of variables having high positive loadings on PC1 points out towards multiple anthropogenic sources (Fig. 2A). These PTEs can be divided into two groups of associated variables, depending on their loadings on PC2: (i) Group I comprising $\mathrm{W}, \mathrm{Sb}, \mathrm{Sn}, \mathrm{Bi}, \mathrm{Hg}$, and $\mathrm{Cu}$ having positive loadings on PC2, and (ii) Group II made up of $\mathrm{Zn}, \mathrm{Cd}$, and B having negative loadings on PC2. Various sources have been reported for Group I PTEs, including biomass burning, vehicular traffic (non-exhaust sources such as brake wear, lubricating oils and corrosion of galvanised vehicular parts), cooking fumes, and industrial activities. ${ }^{4,71-75}$ However, given their association with elements such as nickel ( $\mathrm{Ni})$, sodium $(\mathrm{Na})$, and especially $\mathrm{K}$ (Table S3†), the most likely are smoke-related sources such as cooking, wood burning in stoves and fireplaces, agriculture waste burning and fires occurring in forested areas., ${ }^{\mathbf{4} 65,76}$ Whilst wood burning particulate matter emissions are one of the major emitters of $\mathrm{K}^{+},{ }^{65,76,77}$ the identification of a biomass burning source is usually possible only through the combined use of levoglucosan and $\mathrm{K}^{+}$data because non-biomass burning sources may contribute significantly to atmospheric $\mathrm{K}^{+} \cdot{ }^{78}$ Puxbaum et al. (2007) have found for Aveiro, a coastal city only $15 \mathrm{~km}$ further south from Estarreja, high levels of atmospheric levoglucosan that were interpreted as being associated with the use of wood for domestic heating that is common in north Portugal, forest fires, burning of agricultural and garden waste, and cooking, ${ }^{79}$ which is in agreement with a biomass burning source for Group I PTEs. Also, results from an earlier study indicated that elements such as $\mathrm{K}, \mathrm{Na}$ or $\mathrm{Cd}$ in the indoor dust were related to wood burning in fireplaces in the Estarreja homes. ${ }^{30}$ Hence, the assignment of biomass burning as PTEs source is in good agreement with earlier studies carried out in the region. However, the association of $\mathrm{Na}$ and $\mathrm{K}$ (Table S $\$ \dagger$ ) with Group I PTEs and the coastal location of the city (Fig. S1†) suggest a potential contribution from sea salt. Other studies indicate $\mathrm{Na}$ and $\mathrm{K}$ concentrations in dust has indicators of marine salt. ${ }^{77,80}$ But PTEs such as $\mathrm{W}, \mathrm{Cu}$ and $\mathrm{Hg}$ have been associated with many industrial processes, ${ }^{75}$ another source that has to be taken into account as this is an industrial city. Hereupon, Group I was interpreted as representing mixed biomass burning and anthropogenic pollution, with a contribution from sea salt. Other studies have found mixed anthropogenic sources for PTEs in dust. ${ }^{75,81,82}$

As in Group I, Group II elements ( $\mathrm{Zn}, \mathrm{Cd}$ and B) have significantly higher concentrations $(p<0.05)$ in indoor dust samples (Fig. S4 $\uparrow$ ). Among others, environmental sources of $\mathrm{Zn}$ and $\mathrm{Cd}$ include biomass burning, vehicular traffic and industrial activities. ${ }^{\mathbf{7 0 , 7 3 , 7 5 , 8 2}}$ Main sources of $\mathrm{B}$ to the environment are marine sources (including marshes and lakes), weathering of clay-rich sedimentary rocks, organic matter and biomass burning, B-containing fertilizers and coal combustion. ${ }^{\mathbf{8 3 , 8 4}}$ Once more, biomass burning, vehicular traffic and industrial activities are likely sources, which explain the association of both Group I and Group II variables to PC1. From the supplementary variables, strontium $(\mathrm{Sr})$ is the only element associated with Group II (negative loading in PC2, Table S3 $\dagger$ ). Since $\mathrm{Sr}$ is often suggested as a suitable tracer of mineral dust and the local geology is composed mainly of sandstones and clay deposits that are enriched in $\mathrm{B}^{\mathbf{4 5 , 8 5}}$ it is possible that anthropogenic particulate matter emitted to the atmosphere settles at ground-level where it mixes with mineral dust and/or soil. Hence, Group II probably represents a mixed biomass burning and anthropogenic pollution, with a contribution from mineral dust/soil. Mineral dust may be easily trapped by footwear and later transported indoors. Overall, PC1 looks like the component associated with biomass burning, vehicular traffic and industrial activities, either influenced by sea salts (Group I) or mineral dust/soil (Group II).

On PC2 (accounting for $13.7 \%$ of the total variance) $\mathrm{Pb}$ and Se are a pair of strongly associated variables (Group III). Vehicle exhaust and biogenic emissions are known to be important Se sources to the atmosphere.$^{\mathbf{8 6 , 8 7}}$ Non-exhaust traffic related materials such as lubricating oil, brake dust and street paint have been indicated as important anthropogenic $\mathrm{Pb}$ sources. ${ }^{73,74}$ Although particles from fresh biomass burning usually do not contain $\mathrm{Pb}$, the element may be introduced to the biomass burning particulates during combustion. ${ }^{88}$ Some authors reported on dust $\mathrm{Pb}$ contents associated with biomass burning. ${ }^{72,88}$ The small number of variables correlated with PC2 (none of the supplementary variables was associated with the component) hampers a reliable assignment of a specific source for $\mathrm{Pb}$ and $\mathrm{Se}$ in the household dust. However, the results obtained and the findings of other studies ${ }^{30,79}$ are in good agreement and provide support to the assumption that these elements mainly originate from biomass burning. Furthermore, $\mathrm{Pb}$ is not correlated with any of the PTEs commonly reported as occurring associated with non-exhaust traffic related materials. ${ }^{6,70,74,75}$

Arsenic and Mo have high positive loadings on PC3 (Fig. 2 and Table $\mathrm{S} 3 \dagger)$. The latter is more concentrated in the indoor dust (Fig. S4 $\dagger$ ), but the differences between indoor and outdoor samples are not significant. The geology of the area is composed mainly of sandstones and clay deposits, where the two elements tend to be concentrated, ${ }^{\mathbf{4 5 , 8 5}}$ providing additional support to the natural origin earlier assigned for As. Furthermore, other crustal elements associated with PC3 (Table S3†) include iron (Fe), Ga, niobium (Nb), and cobalt (Co), which support further the assumption that As and Mo, although enriched (Fig. S3 $\dagger$ ), are related to natural sources.

PC4 (accounting for 8.5\% of the total variance), shows high loadings of $\mathrm{Ca}, \mathrm{Zn}$, and $\mathrm{Bi}$ (Table S3† and Fig. 2). These elements have been associated with a mixed material made up of tire dust, diesel soot, and asphalt pavement debris., ${ }^{6,70,89}$ Some authors indicate $\mathrm{Ca}$ as a typical soil component ${ }^{\mathbf{4}, 51}$ when 
associated to $\mathrm{Si}$ or $\mathrm{Mg}$, which are indicative of a crustal source, while others suggest an association with the wear of asphalt concrete $^{89}$ or building materials. ${ }^{752}$ Adachi and Tainosho (2004) relate $\mathrm{Zn}$ to tire tread. ${ }^{73}$ Although building materials cannot be excluded as a potential source, it is likely that PC4 represents a mixed material made up of tire dust and pavement debris. In this study, the higher concentrations in the indoor dust (Fig. S4†) are significantly different from those determined in outdoor dust samples $(p<0.05)$, suggesting that particles of this mixed material find their way into the home. Thus, PC4 is probably the component related to vehicular traffic or reparation works in the house.

In summary, PC1 is interpreted as the component separating earth crust related elements from those having mixed anthropogenic sources. PC2 probably represents elements associated with biomass burning and PC3 elements (As and Mo) that are naturally enriched in the household dust (Fig. 2B). PC4 is related either to vehicular traffic or reparation works ( $\mathrm{Zn}$ and $\mathrm{Ca}$ ).

The factor scores obtained following PCA were regressed against the $\log$ transformed $\mathrm{Zn}$ and $\mathrm{Pb}$ dust content to apportion the percentage contribution of each identified source to the household pollution. Table 3 presents the linear models obtained. $R^{2}$ shows that the two regression models account for $c a$. $75 \%$ of the total variance, which indicates a good fit and allows the application of MLR. Both regression models are statistically significant $(p<0.001)$. The coefficients displayed in Table 3 were used in eqn (1) to estimate relative contributions from each source, according to the methodology early described.

For $\mathrm{Zn}$, biomass burning, vehicular traffic and industrial activities (assigned to PC1) contribute 44.0\%, PC2 (biomass burning) contributes $21.3 \%$, PC3 (soil resuspension) contributes $5.1 \%$, and vehicular traffic and/or reparation works (assigned to PC4) contributes $29.6 \%$. In the case of Pb, biomass burning, vehicular traffic and industrial activities contribute $21.5 \%$, biomass burning contributes $57.1 \%$, soil resuspension contributes $2.9 \%$, and vehicular traffic and/or reparation works contributes $18.5 \%$. These results are provided in a bar chart as ESI (Fig. S5 $\dagger$ ). It is of note that biomass burning and vehicular traffic are the major sources of the two PTEs. Furthermore, industrial activities and vehicular traffic seem to be more important sources of $\mathrm{Zn}$ than $\mathrm{Pb}$ to the atmosphere (Fig. S5 $\dagger$ ).

Seeking further information on PTE sources for the household dust, cluster analysis (CA) was performed using the PCs obtained from the PCA. The $k$-means algorithm used searches for a local solution that minimises the Euclidean distance between the observations and the cluster centres. ${ }^{\mathbf{9 0 9}}{ }^{\mathbf{9 1}} \mathrm{A}$ major obstacle in using $k$-means is that the number of clusters $(k)$ must be assigned a priori. Given that there was no pre-existing knowledge on the number of clusters to expect, a hierarchical
CA was performed first to define the number of clusters. Ward's criteria and the squared Euclidean distance among withinclusters observations were used to compute the proximities. Using the elbow rule, the number of clusters was set as being equal to five. Then, the $k$-means procedure was employed to form the clusters. A $k$-means following the hierarchical analysis had the advantage of minimising the impact of outlier points on the solution. ${ }^{92}$ The five clusters were interpreted through the mean PCs values (Tables S3 and S4 $\dagger$ ).

Cluster I is similar to PC2 and PC4 (Table S4 $\dagger$ ), Cluster II is similar to PC1, PC2 and PC4 (negative scores), Cluster IV is close to the profiles of PC4 and PC2 (negative scores of PC2), Cluster V is only similar to the profile of PC1 (negative scores) and Cluster III is different from them all (Table S4 $\dagger$ ). Hence, from Tables S2 and $\mathrm{S} 3, \dagger$ the clusters are composed by:

Cluster I: W.

Cluster II: $\mathrm{B}+\mathrm{Bi}+\mathrm{Cu}+\mathrm{Cd}+\mathrm{Sb}+\mathrm{Sn}+\mathrm{Hg}+\mathrm{Zn}+\mathrm{W}+\mathrm{Ca}+$ $(\mathrm{Na}+\mathrm{K})$.

Cluster IV: $\mathrm{Pb}+\mathrm{Se}$.

Cluster V: As.

Tungsten has many industrial and military applications. Also, some phosphate fertilisers may contain significant concentrations of $\mathrm{W}$. House appliances with $\mathrm{W}$ include lighting applications (metal wires, coils, etc.) and electrical contacts. ${ }^{93}$ Although $\mathrm{W}$ is a Group I variable (Fig. 2) possibly associated to vehicular traffic and industrial activities, it is possible that unlike other Group I elements, its content in some indoor dust samples is also influenced by a variety of house appliances. Given that Cluster II is similar to the profiles of PC1, PC2 and PC4, the samples within the cluster are interpreted as the ones having mixed anthropogenic sources (industry, vehicular traffic, reparation works and biomass burning with contributions from sea salt and mineral dust). Cluster IV samples are probably related to biomass burning and Cluster $\mathrm{V}$ to soil resuspension.

Following the CA, the predicted cluster membership was set to be the categorical variable of the LDA. Once the different chemical signatures determined had been associated with a particular environmental source, it was necessary to check whether the clusters were statistically significant and the chemical signatures discriminated well the five clusters. Furthermore, one of the aims was to assess whether the identified chemical signatures (clusters) discriminated well indoor from outdoor dust samples.

Table 55 of the ESI $\dagger$ presents the sample classification matrix for the LDA models. The rows show the CA membership of the samples and the columns show the classifications given by the LDA models. Based on Table S5, $\dagger$ only one sample of Cluster II was misclassified. Overall, this indicates that the LDA models classify with accuracy the CA membership.

Table 3 Multiple linear regression models obtained for $\mathrm{Pb}$ and $\mathrm{Zn}$ contents in the house dust

\begin{tabular}{|c|c|c|c|}
\hline & Stepwise MLR model & $R^{2}$ & ${ }^{a}$ Std. error \\
\hline $\mathrm{Zn}$ & {$[\log \mathrm{Zn}]_{\text {dust }}=2.972+0.085 \mathrm{PC} 3+0.331 \mathrm{PC} 1-0.284 \mathrm{PC} 2-0.501 \mathrm{PC} 4$} & 0.75 & 0.18 \\
\hline $\mathrm{Pb}$ & {$[\log \mathrm{Pb}]_{\text {dust }}=2.009-0.031 \mathrm{PC} 3+0.226 \mathrm{PC} 1-0.603 \mathrm{PC} 2+0.195 \mathrm{PC} 4$} & 0.75 & 0.17 \\
\hline
\end{tabular}

${ }^{a}$ Standard error of the estimate. 
The discriminant plot of the standardized canonical coefficients is presented in Fig. 3. Notably evident is the vertical separation between indoor and outdoor samples associated with the first discriminant function (Function 1). Thus, Function 1, which accounts for the majority of the overall variability $(64.5 \%)$, separates the indoor (represented by squares) from the outdoor (represented by dots) samples, which have distinct chemical signatures. However, the second discriminant function (Function 2), accounting for $20.9 \%$ of the total variance and highly significant $(p<0.0001)$, seems to separate samples impacted mainly by biomass burning.

In brief, the multivariate analysis ultimately separated three groups of household dust samples having distinct characteristics: (i) one group comprising the majority of the outdoor dust samples with a chemical signature typical of crustal sources; (ii) one group comprising the majority of the indoor dust samples, impacted by biomass burning and mixed anthropogenic sources with contributions from sea salts and mineral dust/soil, and; (iii) one group made up of both indoor and outdoor dust with a chemical signature indicative of biomass burning. Hence, the combination of the different statistical techniques allowed assessing different chemical signatures that were used to apportion and identify sources of PTEs, both in the indoor and outdoor household dust.

\subsection{Exposure biomarkers relationships}

Before performing the stepwise MLR, the random forest (RF) algorithm was used as a screening technique to identify lifestyle factors or characteristics of the physical environment of the

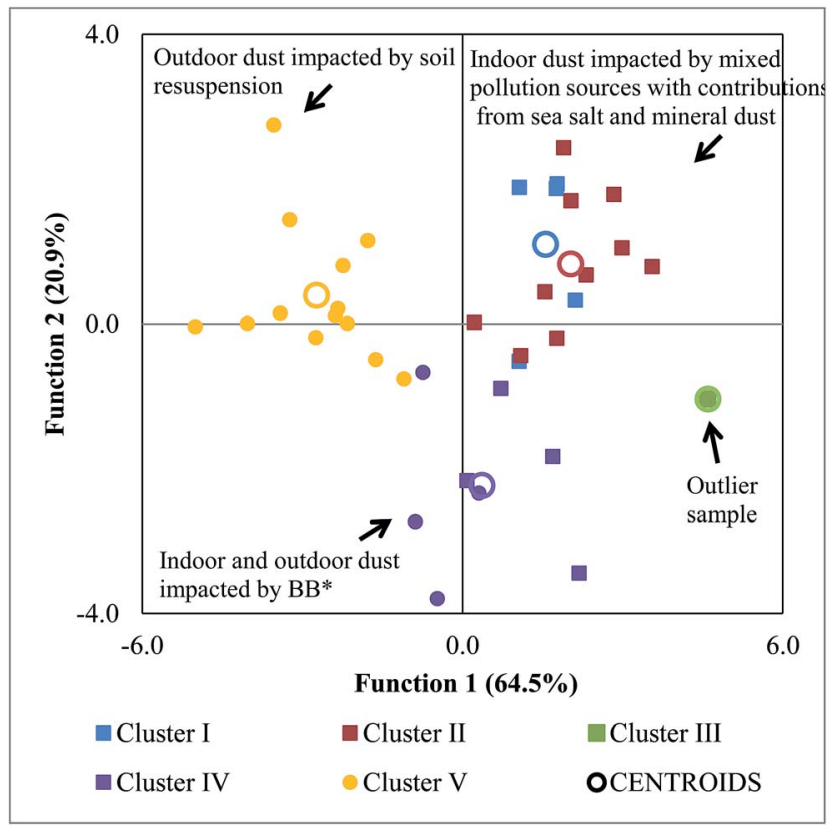

Fig. 3 Results from the discriminant analysis performed using the predicted cluster membership as the categorical variable. Outdoor dust samples are represented by dots while indoor dust is represented by squares. Clusters I and II (in blue and red) contain $74 \%$ of the indoor dust samples and Cluster $V$ (in yellow) contains $78 \%$ of the outdoor dust samples. *BB: biomass burning. house that could influence the relationships between toenail and environmental data. Such factors were used later in the MLR analysis. Hence, element concentrations in toenails were modelled using the elemental composition of indoor dust and lifestyle factors to provide further information on the indoor dust ingestion pathway. A brief summary of the results is presented in the ESI (Table S6, Fig. S6 and S7†).

In the $\mathrm{RF}$ analysis, indoor dust $\mathrm{Pb}$ contents did not arise as a good predictor of toenail $\mathrm{Pb}$. Other environmental and lifestyle factors seemed to be better predictors (Table S6 and Fig. S6†). Residents that consume home-reared poultry, which was one of the best predictors, have more elevated toenail $\mathrm{Pb}$ contents. The area of the house was another good predictor of the toenail data with individuals living in smaller houses having more elevated $\mathrm{Pb}$ contents. The type of water used to cook, shower and wash was also a good predictor of toenail $\mathrm{Pb}$, but the relationship is influenced by a couple of residents that use water from their private well (Fig. S6†).

Indoor dust $\mathrm{Zn}$ contents were a good predictor of toenail $\mathrm{Zn}$, but the relationship seems to be influenced by factors such as the age of the house and reparation works (Table S6 and Fig. S7†). Residents of homes that have had recent reparation works have less elevated toenail $\mathrm{Zn}$ contents, which is probably due to intense housekeeping that usually takes place after such reconstruction works. The relationship between the age of the house and toenail $\mathrm{Zn}$ is not linear and therefore more difficult to interpret, but the trend is that individuals living in younger houses are those having more elevated toenail $\mathrm{Zn}$ contents.

To assess indoor dust ingestion as a potential exposure pathway in the home environment, a stepwise MLR analysis was performed using toenail data as the dependent variable and indoor dust PTEs contents as independent variables. Chemical elements having an EF $>10$ were the ones included in the analysis. Based on the RF results (Table S6†), the area of the house and home-reared poultry consumption, the age of the house and reparation works were used to model toenail $\mathrm{Pb}$ and toenail $\mathrm{Zn}$, respectively. The linear models obtained are shown in Table 4.

$R^{2}$ indicates the proportion of the variance in toenail $\mathrm{Pb}$ and Zn contents accounted for by each regression model. All models are statistically significant $(p<0.005)$. However, the DurbinWatson value of $d=1.4$ obtained for the $\mathrm{Pb}$ model does not fall in the interval defined by the two critical values of $1.5<d<2.5$ and, therefore, we cannot assume that there is no first order linear auto-correlation in our MLR data, that is, that we have an independence of observations. In addition, the standard error of the estimate is higher for the model of $\mathrm{Pb}$ than for those of $\mathrm{Zn}$, indicating a better accuracy of predictions for the later.

Stepwise MLR performed for toenail Zn levels indicates that $\mathrm{Zn}$ and $\mathrm{Sb}$ contents in the indoor dust are both predictor variables once the $R^{2}$ of model 2 is considerably higher than that of model 1 (Table 4). Hence, indoor dust ingestion seems to be a probable exposure pathway to environmental Zn. Antimony, like $\mathrm{Zn}$ and unlike other PTEs sharing the same environmental sources, is anomalously enriched in the indoor dust ( $\mathrm{EF}>100)$, which may explain why it comes out as a good predictor of toenail Zn. The element is usually highly bioaccessible (Table 
Table 4 Stepwise multiple linear regression models obtained for $\mathrm{Pb}$ and $\mathrm{Zn}$ contents in the toenail clippings

\begin{tabular}{llll}
\hline & Stepwise MLR model & $R^{2}$ & ${ }^{a_{\text {Std. error }}}$ \\
\hline $\mathrm{Pb}$ & {$[\log \mathrm{Pb}]_{\text {toenails }}=4.467-1.618[\mathrm{Sn}]_{\text {dust }}$} & 0.42 & 0.34 \\
$\mathrm{Zn}($ model 1) & {$[\mathrm{Zn}]_{\text {toenails }}=1.239+0.274[\mathrm{Zn}]_{\text {dust }}$} & 0.23 & 0.094 \\
$\mathrm{Zn}($ model 2) & {$[\mathrm{Zn}]_{\text {toenails }}=1.239+0.274[\mathrm{Zn}]_{\text {dust }}+0.163[\mathrm{Sb}]_{\text {dust }}$} & 0.40 & 0.084 \\
${ }^{a}$ Standard error of the estimate. & & &
\end{tabular}

$\mathrm{S} 2 \dagger$ ), which means that almost all $\mathrm{Zn}$ in the indoor dust is available to be absorbed in the gastrointestinal tract following ingestion. The bioaccessible fraction of $\mathrm{Pb}$ is extremely variable between samples (ranges from 21 to $82 \%$ ), indicating that the total concentrations can hardly be representative of the oral bioaccessibility, and therefore of the oral bioavailability. It is of note that the absorbed dose in the human body is ultimately controlled by the element's bioavailability. Bioaccessible concentrations and toenail contents were plotted in $X Y$ graphs to assess whether the bioaccessibility influenced the toenail contents (Fig. S8 $\dagger$ ). Looking at the graph (a), a positive trend is observable where increasing concentrations of bioaccessible $\mathrm{Zn}$ in the indoor dust correspond to increasing toenail $\mathrm{Zn}$ contents. For $\mathrm{Pb}$, the points are randomly distributed, indicating that the variables are uncorrelated. The Spearman correlation coefficient calculated for $\mathrm{Pb}(r=0.43, p>0.05)$ and $\mathrm{Zn}(r=0.51, p<$ 0.05 ) confirm the relationships displayed in the figure. We used total $\mathrm{Pb}$ concentrations in the dust to identify relationships with the biomarker, which, according to the results of the bioaccessibility testing, do not reflect the amount of $\mathrm{Pb}$ actually available for absorption in the GI tract. Therefore, for this element, the absence of a correlation is not entirely unexpected. Although the subset of 8 samples used to estimate the Zn bioaccessibility is small, the low variability between the randomly selected samples (Table $\mathrm{S} 2 \dagger$ ) allows extrapolating the relationships obtained to the entire set with a certain degree of confidence.

However, a $40 \%$ value for the total variance explained by the stepwise MLR model of $\mathrm{Zn}$ (Table 4) indicates that the results must be interpreted with caution. In this study, a single exposure pathway was investigated, which is surely insufficient to substantiate the toenail data to its full extent. In fact, the RF analysis indicated home-reared poultry consumption as a predictor of toenail data, although the relationship was not later confirmed by the stepwise MLR analysis. An increasing number of studies has been indicating the ingestion of foodstuffs, either commercial or home-grown, as a significant pathway of exposure to PTEs. ${ }^{94-97}$ Some authors have found noncarcinogenic risks associated mainly with rice, vegetables, and household dust ingestion for adults, and with household dust for young children, ${ }^{\mathbf{9}}$ pointing out towards the importance of the two exposure pathways.

\section{Conclusion}

The small amount of settled dust usually available for collection from indoor environments (highly depending on housekeeping), often limits the number of analytical procedures (dust chemistry, physicochemical properties, mineralogy, bioaccessibility, isotope measurements, solid-phase fractionation, etc.) that can be utilised. As we were facing the problem in this particular study, it was necessary to compromise. Given the impossibility of running further analyses such as isotope measurements, a useful tool for source identification and apportionment, we developed a methodology combining different techniques of multivariate analysis to characterise and quantify PTEs sources. The approach had the advantage of allowing evaluating multiple chemicals and developing a sitespecific geochemical profile. Furthermore, the results obtained were later integrated with toenail data to produce a source-pathway-receptor model.

The proposed methodology provided information on sources, pathways, and the fate of $\mathrm{Pb}$ and $\mathrm{Zn}$ that can be summarised as follows:

(1) The measured toenails concentrations were slightly higher than the ranges found for healthy people available from the literature.

(2) The enrichment factor showed that $\mathrm{B}, \mathrm{Bi}, \mathrm{Ca}, \mathrm{Cu}, \mathrm{As}, \mathrm{Se}$, Mo, Cd, Sn, W, Pb, and $\mathrm{Hg}$ are enriched $(10<\mathrm{EF}<100)$ and $\mathrm{Zn}$ and $\mathrm{Sb}(\mathrm{EF}>100)$ are anomalously enriched in the household dust, indicating a potential exposure to these PTEs in the home environment.

(3) Multivariate analysis performed in a PCA-CA-LDA sequence separated three groups of household dust samples having distinct characteristics: (i) one group comprising the majority of the outdoor dust samples with a chemical signature (As, Mo) typical of crustal sources; (ii) one group comprising the majority of the indoor dust samples, impacted by biomass burning and mixed anthropogenic sources (Bi, Cu, Cd, Sb, Sn, $\mathrm{Hg}, \mathrm{Zn}, \mathrm{W}, \mathrm{Ca}$ ) with contributions from sea salts $(\mathrm{Na}, \mathrm{K})$ and mineral dust/soil (B), and; (iii) one group made up of both indoor and outdoor dust with a chemical signature indicative of biomass burning ( $\mathrm{Pb}, \mathrm{Se})$.

(4) Stepwise MLR indicates that $\mathrm{Zn}$ and $\mathrm{Sb}$ concentrations in the indoor dust are the predictor variables for toenail $\mathrm{Zn}$ contents. Given the likelihood of a first-order linear autocorrelation in our multiple linear regression data, the statistical model obtained for toenail $\mathrm{Pb}$ was considered unreliable.

(5) A positive linear relationship $\left(R^{2}=0.61\right)$ was observed between bioaccessible $\mathrm{Zn}$ concentrations and toenail $\mathrm{Zn}$ contents, which was confirmed by a statistically significant $(p<$ $0.05)$ correlation $(r=0.51)$ between the two variables. Unlike $\mathrm{Zn}$, the bioaccessibility of $\mathrm{Pb}$ is highly variable between samples. Both results suggest that the oral bioaccessibility of the PTEs influences the exposure-biomarker relationship. 
However, the obtained MLR model, although highly significant, explains a small part of the total variance. Exposure pathways other than dust ingestion are probably contributing to the body metal burden of the participants. Nevertheless, the developed methodology proved to be effective to identify and characterize potential sources of PTEs in the Estarreja region, despite the complexity and limitations associated with our datasets. Hence, evidence suggests that the same methodology has the potential to be applied to a broad range of environmental scenarios for data integration and management, which can be useful to researchers and environmental assessors.

\section{Conflicts of interest}

There are no conflicts to declare.

\section{Acknowledgements}

Funding for this research was provided by the Labex DRIIHM, French programme "Investissements d'Avenir" (ANR-11-LABX0010) which is managed by the ANR. We thank the participants for taking part in this research. We also thank the Centro de Saúde and the Câmara Municipal de Estarreja for the collaboration. We acknowledge to the Foundation for Science and the Technology (FCT) the support to the Project UID/GEO/ 04035/2013.

\section{References}

1 L. Chang, P. Koutrakis, P. Catalano and H. Suh, Assessing the Importance of Different Exposure Metrics and TimeActivity Data to Predict 24-H Personal $\mathrm{PM}_{2.5}$ Exposures, $J$. Toxicol. Environ. Health, Part A, 2003, 66(16-19), 1825-1846.

2 F. J. Kelly and J. C. Fussell, Air pollution and public health: emerging hazards and improved understanding of risk, Environ. Geochem. Health, 2015, 37(4), 631-649.

3 F. Amato, I. Rivas, M. Viana, T. Moreno, L. Bouso, C. Reche, et al., Sources of indoor and outdoor $\mathrm{PM}_{2.5}$ concentrations in primary schools, Sci. Total Environ., 2014, 490, 757-765, DOI: 10.1016/j.scitotenv.2014.05.051.

4 A. Bari, W. B. Kindzierski, L. A. Wallace, A. J. Wheeler, M. Macneill and M.-È. Héroux, Indoor and Outdoor Levels and Sources of Submicron Particles (PM1) at Homes in Edmonton, Environ. Sci. Technol., 2015, 49, 6419-6429.

5 M. D. Geller, M. Chang, C. Sioutas, B. D. Ostro and M. J. Lipsett, Indoor/outdoor relationship and chemical composition of fine and coarse particles in the southern California deserts, Atmos. Environ., 2002, 36, 1099-1110.

6 C.-Y. Kuo, J.-Y. Wang, W.-T. Liu, P.-Y. Lin, C.-T. Tsai and M.-T. Cheng, Evaluation of the vehicle contributions of metals to indoor environments, J. Exposure Sci. Environ. Epidemiol., 2012, 22(5), 489-495, DOI: 10.1038/jes.2012.55.

7 D. D. Massey, A. Kulshrestha and A. Taneja, Particulate matter concentrations and their related metal toxicity in rural residential environment of semi-arid region of India, Atmos. Environ., 2013, 67, 278-286.
8 P. E. Rasmussen, K. S. Subramanian and B. J. Jessiman, A multi-element profile of housedust in relation to exterior dust and soils in the city of Ottawa, Canada, Sci. Total Environ., 2001, 267, 125-140.

9 B. Yaghi and S. A. A. Wahab, Levels of heavy metals in outdoor and indoor dusts in Muscat, Oman, Int. J. Environ. Stud., 2004, 61(3), 307-314.

10 ATSDR, Public Health Statement for Arsenic. Agency for Toxic Substances and Disease Registry, Division of Toxicology and Environmental Medicine, Atlanta, Georgia, 2007, https:// www.atsdr.cdc.gov/ToxProfiles/tp2-c1-b.pdf, accessed September 2017.

11 B. P. Lanphear, R. Hornung, J. Khoury, K. Yolton, P. Baghurst, D. C. Bellinger, et al., Low-Level Environmental Lead Exposure and Children's Intellectual Function: An International Pooled Analysis, Environ. Health Perspect., 2005, 113(7), 894-899.

12 L. M. Chiodo, C. Covington, R. J. Sokol, J. H. Hannigan, J. Jannise, J. Ager, et al., Blood lead levels and specific attention effects in young children, Neurotoxicol. Teratol, 2007, 29, 538-546.

13 S. Plumejeaud, A. P. Reis, V. Tassistro, C. Patinha, Y. Noack and T. Orsière, Potentially harmful elements in house dust from Estarreja, Portugal: characterization and genotoxicity of the bioaccessible fraction, Environ. Geochem. Health, 2018, 127-144.

14 M. P. Cuajungco and G. J. Lees, Zinc Metabolism in the Brain: Relevance to Human Neurodegenerative Disorders, Neurobiol. Dis., 1997, 4, 137-169.

$15 \mathrm{~J}$. Nriagu, Zinc in the Environment. Part 2: Health Effects, ed. J. Nriagu, New York, Wiley, 1980.

16 S. Beauchemin, L. C. W. MacLean and P. E. Rasmussen, Lead speciation in indoor dust: A case study to assess old paint contribution in a Canadian urban house, Environ. Geochem. Health, 2011, 33(4), 343-352.

17 P. E. Rasmussen, C. Levesque, M. Chénier, H. D. Gardner, H. Jones-Otazo and S. Petrovic, Canadian House Dust Study: Population-based concentrations, loads and loading rates of arsenic, cadmium, chromium, copper, nickel, lead, and zinc inside urban homes, Sci. Total Environ., 2013, 443, 520-529, DOI: 10.1016/j.scitotenv.2012.11.003.

18 F. Barbosa Jr, J. E. Tanus-Santos, R. F. Gerlach and P. J. Parsons, A Critical Review of Biomarkers Used for Monitoring Human Exposure to Lead: Advantages, Limitations, and Future Needs, Environ. Health Perspect., 2005, 113(12), 1669-1674.

19 S. Cao, X. Duan, X. Zhao, B. Wang, J. Ma, D. Fan, et al., Isotopic ratio based source apportionment of children's blood lead around coking plant area, Environ. Int., 2014, 73, 158-166, DOI: 10.1016/j.envint.2014.07.015.

20 P. Coelho, S. Costa, S. Silva, A. Walter, J. Ranville, A. C. A. Sousa, et al., Metal(loid) Levels in Biological Matrices from Human Populations Exposed to Mining Contamination-Panasqueira Mine (Portugal), J. Toxicol. Environ. Health, Part A, 2012, 75(13-15), 893-908.

21 W. Ndilila, A. C. Callan, L. A. McGregor, R. M. Kalin and A. L. Hinwood, Environmental and toenail metals 
concentrations in copper mining and non-mining communities in Zambia, Int. J. Hyg. Environ. Health, 2014, 217(1), 62-69, DOI: 10.1016/j.ijheh.2013.03.011.

22 S. Cao, X. Duan, X. Zhao, B. Wang, J. Ma, D. Fan, et al., Levels and source apportionment of children's lead exposure: Could urinary lead be used to identify the levels and sources of children's lead pollution?, Environ. Pollut., 2015, 199, 18-25, DOI: 10.1016/j.envpol.2014.12.035.

23 J. P. Goullé, E. Saussereau, L. Mahieu, D. Bouige, S. Groenwont, M. Guerbet, et al., Application of Inductively Coupled Plasma Mass Spectrometry Multielement Analysis in Fingernail and Toenail as a Biomarker of Metal Exposure, J. Anal. Toxicol., 2009, 33, 92-98.

$24 \mathrm{~K}$. He, Trace Elements in Nails as Biomarkers in Clinical Research, Eur. J. Clin. Invest., 2011, 41(1), 98-102.

$25 \mathrm{H}$. Cheng and Y. Hu, Lead (Pb) isotopic fingerprinting and its applications in lead pollution studies in China: A review, Environ. Pollut., 2010, 158(5), 1134-1146, DOI: 10.1016/j.envpol.2009.12.028.

26 T. R. Dallmann, T. B. Onasch, T. W. Kirchstetter, D. R. Worton, E. C. Fortner, S. C. Herndon, et al., Characterization of particulate matter emissions from onroad gasoline and diesel vehicles using a soot particle aerosol mass spectrometer, Atmos. Chem. Phys., 2014, 14(14), 7585-7599.

27 H. Ha, J. R. Olson, L. Bian and P. A. Rogerson, Analysis of heavy metal sources in soil using kriging interpolation on principal components, Environ. Sci. Technol., 2014, 48(9), 4999-5007.

28 A. P. Marinho Reis, T. Shepherd, G. Nowell, A. Cachada, A. C. Duarte, M. Cave, et al., Source and pathway analysis of lead and polycyclic aromatic hydrocarbons in Lisbon urban soils, Sci. Total Environ., 2016, 573, 324-336, DOI: 10.1016/j.scitotenv.2016.08.119.

29 B. J. Tunno, R. Dalton, L. Cambal, F. Holguin, P. Lioy and J. E. Clougherty, Indoor source apportionment in urban communities near industrial sites, Atmos. Environ., 2016, 139, 30-36, DOI: 10.1016/j.atmosenv.2016.04.039.

30 A. P. Reis, S. Costa, I. Santos, C. Patinha, Y. Noack, J. Wragg, et al., Investigating relationships between biomarkers of exposure and environmental copper and manganese levels in house dusts from a Portuguese industrial city, Environ. Geochem. Health, 2015, 37, 725-744, DOI: 10.1007/s10653015-9724-x.

31 W. Zhang, Y. Tong, H. Wang, L. Chen, L. Ou, X. Wang, et al., Emission of Metals from Pelletized and Uncompressed Biomass Fuels Combustion in Rural Household Stoves in China, Sci. Rep., 2015, 4, 5611.

32 M. Hasan, A. Salam and A. M. S. Alam, Identification and characterization of trace metals in black solid materials deposited from biomass burning at the cooking stoves in Bangladesh, Biomass Bioenergy, 2009, 33(10), 1376-1380, DOI: $10.1016 /$ j.biombioe.2009.05.023.

33 E. Morillo, A. S. Romero, L. Madrid, J. Villaverde and C. Maqueda, Characterization and sources of PAHs and potentially toxic metals in urban environments of Sevilla (southern Spain), Water, Air, Soil Pollut., 2008, 187(1-4), 41-51.

34 C. Patinha, N. Durães, P. Sousa, A. C. Dias, A. P. Reis, Y. Noack, et al., Assessment of the influence of trafficrelated particles in urban dust using sequential selective extraction and oral bioaccessibility tests, Environ. Geochem. Health, 2015, 37(4), 707-724.

35 J. Ridgway, N. Breward, W. J. Langston, R. Lister, J. G. Rees and S. M. Rowlatt, Distinguishing between natural and anthropogenic sources of metals entering the Irish Sea, Appl. Geochem., 2003, 18, 283-309.

36 C. Patinha, N. Durães, A. C. Dias, P. Pato, R. Fonseca, A. Janeiro, et al., Long-term application of the organic and inorganic pesticides in vineyards: Environmental record of past use, Appl. Geochem., 2018, 88(Part B), 226-238, DOI: 10.1016/j.apgeochem.2017.05.014.

37 A. P. Reis, E. F. Silva, E. C. Fonseca, C. Patinha, C. Barrosinho and J. Matos, Environmental Assessment of the Caveira Abandoned Mine (Southern Portugal): Part 1 : Characterization of Metal Contaminated Soil, Soil Sediment Contam., 2012, 21(2), 227-254.

38 A. Facchinelli, E. Sacchi and L. Mallen, Multivariate statistical and GIS-based approach to identify heavy metal sources in soils, Environ. Pollut., 2001, 114, 313-324.

39 H. Yongming, D. Peixuan, C. Junji and E. S. Posmentier, Multivariate analysis of heavy metal contamination in urban dusts of Xi'an, Central China, Sci. Total Environ., 2006, 355(1-3), 176-186.

40 C. K. Singh, A. Kumar, S. Shashtri, A. Kumar, P. Kumar and J. Mallick, Multivariate statistical analysis and geochemical modeling for geochemical assessment of groundwater of Delhi, India, J. Geochem. Explor., 2017, 175, 59-71, DOI: 10.1016/j.gexplo.2017.01.001.

41 CCDR, 2011, DATACENTRO, Informação para a região, http://datacentro.ccdrc.pt/, accessed on January 2017.

42 M. L. Figueiredo, A. Monteiro, M. Lopes, J. Ferreira and C. Borrego, Air quality assessment of Estarreja, an urban industrialized area, in a coastal region of Portugal, Environ. Monit. Assess., 2013, 185(7), 5847-5860.

43 M. E. Pereira, A. I. Lillebø, P. Pato, M. Válega, J. P. Coelho, C. B. Lopes, et al., Mercury pollution in Ria de Aveiro (Portugal): A review of the system assessment, Environ. Monit. Assess., 2009, 155(1-4), 39-49.

44 M. Inácio, O. Neves, V. Pereira and E. Ferreira da Silva, Levels of selected potential harmful elements (PHEs) in soils and vegetables used in diet of the population living in the surroundings of the Estarreja Chemical Complex (Portugal), Appl. Geochem., 2014, 44, 38-44.

45 M. M. S. Cabral, A. P. Marinho-Reis, M. A. Almeida, C. M. Ordens, M. M. V. G. Silva, S. Freitas, et al., Human predisposition to cognitive impairment and its relation with environmental exposure to potentially toxic elements, Environ. Geochem. Health, 2017, DOI: 10.1007/s10653-0179928-3 [Epub ahead of print].

46 C. Patinha, A. P. Reis, A. C. Dias, A. A. Abduljelil, Y. Noack, S. Robert, et al., The mobility and human oral 
bioaccessibility of $\mathrm{Zn}$ and $\mathrm{Pb}$ in urban dusts of Estarreja ( $\mathrm{N}$ Portugal), Environ. Geochem. Health, 2015, 37(1), 115-131.

47 APA, Agência Portuguesa do Ambiente. QualAr, Base de Dados Online sobre a Qualidade do Ar, 2017, http:// qualar.apambiente.pt/, accessed on January 2017.

48 A. L. Juhasz, J. Weber and E. Smith, Impact of soil particle size and bioaccessibility on children and adult lead exposure in peri-urban contaminated soils, J. Hazard. Mater., 2011, 186(2-3), 1870-1879, DOI: 10.1016/ j.jhazmat.2010.12.095.

49 J. Bierkens, M. Van Holderbeke, C. Cornelis and R. Torfs, Exposure through soil and dust ingestion, in Dealing with contaminated sites, ed. F. A. Swartjes, Springer, Berlin, 2011, pp. 261-286, DOI: 10.1007/978-90-481-9757-6_6.

50 J. Wragg, M. Cave, N. Basta, E. Brandon, S. Casteel, S. Denys, et al., An inter-laboratory trial of the unified BARGE bioaccessibility method for arsenic, cadmium and lead in soil, Sci. Total Environ., 2011, 409(19), 4016-4030, DOI: 10.1016/j.scitotenv.2011.05.019.

51 J. N. M. Zhong, M. T. Latif, N. Mohamad, N. Bahiyah, A. Wahid, D. Dominick, et al., Source Apportionment of Particulate Matter $\left(\mathrm{PM}_{10}\right)$ and Indoor Dust in a University Building, Environ. Forensics, 2014, 15, 8-16.

52 I. T. Jollife, Principal component analysis, 2nd edn, SpringerVerlag, NewYork, 2002.

53 A. P. Reis, E. F. Silva, A. J. Sousa, C. Patinha, E. Martins, C. Guimaraes, et al., Geochemical associations and their spatial patterns of variation in soil data from the Marrancos gold-tungsten deposit: a pilot analysis, Geochem.: Explor., Environ., Anal., 2009, 9, 319-340.

54 A. P. Reis, A. J. Sousa and E. C. Fonseca, Application of geostatistical methods in gold geochemical anomalies identification (Montemor-O-Novo, Portugal), J. Geochem. Explor., 2003, 77, 45-63.

55 R. K. Larsen and J. E. Baker, Source Apportionment of Polycyclic Aromatic Hydrocarbons in the Urban Atmosphere: A Comparison of Three Methods, Environ. Sci. Technol., 2003, 37(9), 1873-1881.

56 Q. Zuo, Y. H. Duan, Y. Yang, X. J. Wang and S. Tao, Source apportionment of polycyclic aromatic hydrocarbons in surface soil in Tianjin, China, Environ. Pollut., 2007, 147, 303-310.

57 R. H. Anderson, D. B. Farrar and S. R. Thoms, Application of discriminant analysis with clustered data to determine anthropogenic metals contamination, Sci. Total Environ., 2009, 408(1), 50-56, DOI: 10.1016/j.scitotenv.2009.09.019.

58 R. Grashow, J. Zhang, S. C. Fang, M. G. Weisskopf, D. C. Christiani and J. M. Cavallari, Occupational Welding Fume Exposure Toenail Metal Concentration as a Biomarker of Occupational Welding Fume Exposure, $J$. Occup. Environ. Hyg., 2014, 11(6), 397-405.

59 N. M. Lowe, K. Fekete and T. Decsi, Methods of assessment of zinc status in humans: a systematic review, Am. J. Clin. Nutr., 2009, 89, 2040-2051.

60 D. J. Paustenbach, B. L. Finley and T. F. Long, The critical role of house dust in understanding the hazards posed by contaminated soil, Int. J. Toxicol., 1997, 16, 339-362.
61 M. N. Rashed, Total and Extractable Heavy Metals in Indoor, Outdoor and Street Dust from Aswan City, Egypt, Clean: Soil, Air, Water, 2008, 36(10-11), 850-857.

62 M. Chabukdhara and A. K. Nema, Heavy metals assessment in urban soil around industrial clusters in Ghaziabad, India: Probabilistic health risk approach, Ecotoxicol. Environ. Saf., 2013, 87, 57-64, DOI: 10.1016/j.ecoenv.2012.08.032.

63 M. Izquierdo, E. D. Miguel, M. F. Ortega and J. Mingot, Bioaccessibility of metals and human health risk assessment in community urban gardens, Chemosphere, 2015, 135, 312-318, DOI: 10.1016/ j.chemosphere.2015.04.079.

64 A. P. Reis, C. Patinha, Y. Noack, S. Robert, A. C. Dias and E. Ferreira, Assessing the human health risk for aluminium, zinc and lead in outdoor dusts collected in recreational sites used by children at an industrial area in the western part of the Bassin Minier de Provence, France, J. Afr. Earth Sci., 2014, 99, 724-734, DOI: 10.1016/ j.jafrearsci.2013.08.001.

65 R. Betha, S. N. Behera and R. Balasubramanian, 2013 Southeast Asian Smoke Haze: Fractionation of ParticulateBound Elements and Associated Health Risk, Environ. Sci. Technol., 2014, 48, 4327-4335.

66 H. Li, Q. Wang, M. Yang, F. Li, J. Wang, Y. Sun, et al., Chemical characterization and source apportionment of $\mathrm{PM}_{2.5}$ aerosols in a megacity of Southeast China, Atmos. Res., 2016, 181, 288-299.

67 C. Reimann and P. D. Caritat, Intrinsic Flaws of Element Enrichment Factors (EFs) in Environmental Geochemistry, Environ. Sci. Technol., 2000, 34(24), 5084-5091.

68 R. Rudnick and S. Gao, Composition of the continental crust, in Treatise on Geochemistry, ed. H. D. Holland and K. K. Turekian, Elsevier-Pergamon, Oxford, vol. 3, 2003, pp. 1-64.

69 E. De Miguel, J. F. Llamas, E. Chacón, T. Berg, S. Larssen, O. Royset, et al., Origin and patterns of distribution of trace elements in street dust: unleaded petrol and urban lead, Atmos. Environ., 1997, 31(17), 2733-2740.

70 M. Dall'Osto, D. Beddows, J. Gietl, O. Olatunbosun, X. Yang and R. M. Harrison, Characteristics of tyre dust in polluted air: Studies by single particle mass spectrometry (ATOFMS), Atmos. Environ., 2014, 94, 224-230, DOI: 10.1016/j.atmosenv.2014.05.026.

71 B. Pekey, Z. B. Bozkurt, H. Pekey, G. Dogan, A. Zararsiz, N. Efe, et al., Indoor/outdoor concentrations and elemental composition of $\mathrm{PM}_{10} / \mathrm{PM}_{2.5}$ in urban/industrial areas of Kocaeli City, Turkey, Indoor Air, 2010, 20, 112-125.

72 M. Ahmed, X. Guo and X.-M. Zhao, Determination and analysis of trace metals and surfactant in air particulate matter during biomass burning haze episode in Malaysia, Atmos. Environ., 2016, 141, 219-229, DOI: 10.1016/ j.atmosenv.2016.06.066.

$73 \mathrm{~K}$. Adachi and Y. Tainosho, Characterization of heavy metal particles embedded in tire dust, Environ. Int., 2004, 30, 10091017.

74 S. Lawrence, R. Sokhi, K. Ravindra, H. Mao, H. D. Prain and I. D. Bull, Source apportionment of traffic emissions of 
particulate matter using tunnel measurements, Atmos. Environ., 2013, 77, 548-557, DOI: 10.1016/ j.atmosenv.2013.03.040.

75 A. Najmeddin, F. Moore, B. Keshavarzi and Z. Sadegh, Pollution, source apportionment and health risk of potentially toxic elements (PTEs) and polycyclic aromatic hydrocarbons (PAHs) in urban street dust of Mashhad, the second largest city of Iran, J. Geochem. Explor., 2018, 190, 154-169, DOI: 10.1016/j.gexplo.2018.03.004.

76 C. Reche, M. Viana, F. Amato, A. Alastuey, T. Moreno, R. Hillamo, et al., Biomass burning contributions to urban aerosols in a coastal Mediterranean City, Sci. Total Environ., 2012, 427-428, 175-190, DOI: 10.1016/ j.scitotenv.2012.04.012.

77 S. Yatkin and A. Bayram, Determination of major natural and anthropogenic source profiles for particulate matter and trace elements in Izmir, Turkey, Chemosphere, 2008, 71, 685-696.

78 S. G. Brown, T. Lee, P. T. Roberts and J. L. Collett Jr, Wintertime Residential Biomass Burning in Las Vegas, Nevada; Marker Components and Apportionment Methods, Atmosphere, 2016, 7, 58.

79 H. Puxbaum, A. Caseiro, A. Sánchez-Ochoa, A. Kasper-Giebl, M. Claeys, A. Gelencsér, et al., Levoglucosan levels at background sites in Europe for assessing the impact of biomass combustion on the European aerosol background, J. Geophys. Res., 2007, 112, D23S05.

80 J. Chen, C. Li, Z. Ristovski, A. Milic, Y. Gu, M. S. Islam, et al., A review of biomass burning: Emissions and impacts on air quality, health and climate in China, Sci. Total Environ., 2017, 579, 1000-1034, DOI: 10.1016/j.scitotenv.2016.11.025.

81 F. M. Darus, R. A. Nasir, S. M. Sumari, Z. S. Ismail and N. A. Omar, Heavy Metals Composition of Indoor Dust in Nursery Schools Building, Procedia Soc. Behav. Sci., 2012, 38, 69-75.

82 A. Kulshrestha, D. D. Massey, J. Masih and A. Taneja, Source Characterization of Trace Elements in Indoor Environments at Urban, Rural and Roadside Sites in a Semi-Arid Region of India, Aerosol Air Qual. Res., 2014, 14, 1738-1751.

83 P. D. Howe, A Review of Boron Effects in the Environment, Biol. Trace Elem. Res., 1998, 66, 153-166.

84 Z.-Q. Zhao and C.-Q. Liu, Anthropogenic inputs of boron into urban atmosphere: Evidence from boron isotopes of precipitations in Guiyang City, China, Atmos. Environ., 2010, 44, 4165-4171, DOI: 10.1016/j.atmosenv.2010.07.035.

85 R. Salminen, J. A. Plant and S. Reeder, Geochemical atlas of Europe. Part 1: Background information, methodology and maps, Espoo: Geological survey of Finland, 2005. http:// www.gtk.fi/publ/foregsatlas/, accessed on September 2017.
86 A. De Santiago, A. F. Longo, E. D. Ingall, J. M. Diaz, L. E. King, B. Lai, et al., Characterization of Selenium in Ambient Aerosols and Primary Emission Sources, Environ. Sci. Technol., 2014, 48, 8988-8994.

87 L. Husain, P. P. Parekh, V. A. Dutkiewicz, A. R. Khan, K. Yang and K. Swami, Long-term trends in atmospheric concentrations of sulfate, total sulfur, and trace elements in the northeastern United States, J. Geophys. Res., 2004, 109, D18305.

88 Y. Zhang, X. Wang, H. Chen, X. Yang, J. Chen and J. O. Allen, Source apportionment of lead-containing aerosol particles in Shanghai using single particle mass spectrometry, Chemosphere, 2009, 74(4), 501-507, DOI: 10.1016/ j.chemosphere.2008.10.004.

89 D. Zannoni, G. Valotto, F. Visin and G. Rampazzo, Sources and distribution of tracer elements in road dust: The Venice mainland case of study, J. Geochem. Explor., 2016, 166, 64-72, DOI: 10.1016/j.gexplo.2016.04.007.

90 J. A. Hartigan and M. A. Wong, A K-Means Clustering Algorithm, J. R. Stat. Soc. Ser. C, 1979, 28, 100-108.

91 A. Likas, N. Vlassis and J. J. Verbeek, The global $k$-means clustering algorithm, Pattern Recognition, 2003, 36, 451-461.

92 E. Austin, B. A. Coull, A. Zanobetti and P. Koutrakis, A framework to spatially cluster air pollution monitoring sites in US based on the $\mathrm{PM}_{2.5}$ composition, Environ. Int., 2013, 59, 244-254, DOI: 10.1016/j.envint.2013.06.003.

93 N. Strigul, A. Koutsospyros, P. Arienti, C. Christodoulatos, D. Dermatas and W. Braida, Effects of tungsten on environmental systems, Chemosphere, 2005, 61, 248-258.

94 J. Zheng, K. Chen, X. Yan, S. Chen, G. Hu, X. Peng, et al., Heavy metals in food, house dust, and water from an ewaste recycling area in South China and the potential risk to human health, Ecotoxicol. Environ. Saf., 2013, 96, 205212, DOI: 10.1016/j.ecoenv.2013.06.017.

$95 \mathrm{~J}$. Hu, F. Wu, S. Wu, Z. Cao, X. Lin and M. H. Wong, Bioaccessibility, dietary exposure and human risk assessment of heavy metals from market vegetables in Hong Kong revealed with an in vitro gastrointestinal model, Chemosphere, 2013, 91(4), 455-461, DOI: 10.1016/ j.chemosphere.2012.11.066.

96 R. L. Hough, N. Breward, S. D. Young, N. M. J. Crout, A. M. Tye, A. M. Moir, et al., Assessing Potential Risk of Heavy Metal Exposure from Consumption of HomeProduced Vegetables by Urban Populations, Environ. Health Perspect., 2004, 112(2), 215-221.

97 C. Qu, Z. Ma, J. Yang, Y. Liu, J. Bi and L. Huang, Human Exposure Pathways of Heavy Metals in a Lead- Zinc Mining Area, Jiangsu Province, China, PLoS One, 2012, 7(11), e46793. 